\title{
Research on Integration Development of Liquor Culture and Tourism in China
}

\begin{abstract}
Min Wei and Jie $\mathrm{Xu}^{*}$
School of Management, Xiamen University, China

*Corresponding author. Email:xujie32467@163.com

ABSTRACT

Chinese liquor culture is a complex and comprehensive resource formed by many factors such as local history, culture, society and economy. On the basis of literature review and on-the-spot investigation, this paper analyzes the rich and diverse forms of liquor culture in areas, including liquor culture museum, liquor cultural souvenirs, liquor culture and art, liquor making experience projects, liquor culture folk customs, etc. The findings show that liquor culture tourism can promote the transformation and upgrading of liquor industry. Tourists' shopping demand urges distillers to develop new tourism products. On the one hand, it increases liquor sales, on the other hand, it improves the added value of liquor products. Secondly, liquor culture tourism promotes the common high-quality development of other industries. Due to the increase in the number of tourists, a large number of high demand bursts, which not only promotes tourism production. On this basis, the paper puts forward the development path of integration between liquor culture and tourism.
\end{abstract}

Keywords: Liquor culture, Tourism, Area, Integrated development.

\section{INTRODUCTION}

Areas can play a better advantage in tourism interest, take advantage of the opportunity to integrate liquor culture and tourism, with the whole industry chain as the feature, and the full range of value-added services as the advantages. The community will build an international community integrating culture, commerce, tourism, office and leisure. The community will take liquor as the theme. The planned functional areas include: leisure waterfront, commercial center, copyright Economic Zone, and Commerce and trade Trading area, exhibition area, residential service area, enterprise headquarters base, industrial incubation base, etc. each region undertakes all functional links in the liquor industry chain, including liquor manufacturing, research and development, circulation, consumption and cultural bearing. These links form an organic whole through the commercial axis and industrial integration axis. Tianjin liquor culture industrial park is planned and built according to the requirements of $4 \mathrm{~A}$ level scenic spot, striving to create a $5 \mathrm{~A}$ level tourist attraction of liquor culture and leisure. It receives no less than 1 million tourists, has an annual transaction volume of no less than 30 billion yuan, provides tax revenue of no less than 3 billion yuan, and provides no less than 30000 job opportunities.

Chinese liquor culture is a complex and comprehensive resource formed by many factors such as local history, culture, society, economy, etc. taking liquor as the core, it presents rich and diverse forms of expression, including liquor culture museum, liquor culture souvenirs, liquor culture art, liquor making experience project, liquor culture folk custom, etc., which are both tangible and intangible, and are difficult to use One standard. Therefore, the evaluation of the development value of Wuliangye Liquor cultural tourism resources in Yibin is a more complicated decision-making process, which not only does not need to comprehensively analyze its internal value, but also needs to comprehensively consider many external factors, such as tourist source market and local environment. In view of the fact that there are few articles to evaluate the tourism development value of liquor culture, and liquor culture is also a kind of culture, this topic draws lessons from many studies on the evaluation of tourism development value of cultural resources. In modern times, the integration of liquor culture and tourism industry is everywhere. For example, in 2013, Maotai Liquor Group established a Cultural Tourism Co., Ltd., focusing on developing Maotai 
industrial tourism; in 2014, Wuliangye Group established a tourism culture development Co., Ltd., striving to create a national $5 \mathrm{~A}$ scenic spot.

In the future, the integration of liquor culture tourism industry will be more in-depth. For the liquor culture industry, whether it is the product innovation brought about by the upgrading of liquor making technology or the unit cost reduction caused by industrial production, it cannot continuously promote the industry to achieve a substantial increase in economic benefits. The future development needs to be driven by culture, while the cultural industrialization needs the help of tourism. For the tourism industry, the previous tourism mode of floating on the surface and looking at the flowers has been changed Unable to meet the growing needs of people for a better life, culture is needed to support the development of immersive tourism experience projects. Secondly, cultural heritage and development need cultural tourism integration. This kind of immersive experience activity helps to recognize and spread culture. The integrated development of liquor culture and tourism not only enables people to taste the unique liquor, but also to understand the production process and local liquor tasting customs. This culture will be better protected and inherited because it attracts more tourists. Finally, the development of regional economy is inseparable from the integration of culture and tourism. This paper is concentrated on a path to promote regional development, especially in areas with strong liquor culture. The combination of the two will create employment and wealth for the local area (T. López - Guzmán et al., 2011). At the same time, the development of tourism will promote the development of related industries, such as transportation, infrastructure, etc.

\section{LITERATURE REVIEWS}

The European Commission (1997) thinks that integration is essentially the integration of industrial alliance and merger, technology network platform and market. Industrial convergence is not a simple superposition of two industries, but an all-round integration process of technology, products, enterprises, market, system and mechanism between the two industries, so as to form a new industrial form. Tourism industry is a highly related industry, which is not only reflected in the interaction among the six elements of food, housing, transportation, tourism, shopping and entertainment, but also has extensive relations with the primary and secondary industries. With the continuous improvement of material life, the travel mode of "walking horse and seeing flowers" has been unable to meet people's growing needs for a better life. Cultural resources and cultural creativity enrich the content of tourism and enrich the intrinsic value of tourism itself.
Tourism is an important form of cultural cognition and cultural sharing (Zhang, 2019), which provides an important way for cultural heritage, dissemination and value realization. Therefore, cultural industry also needs to integrate with tourism industry to realize industrial economy. The openness and fuzziness of the boundary between cultural industry and tourism industry provide the possibility for their integrated development. The successive introduction of national policies to promote the integration and development of cultural industry and tourism industry has provided external support and promotion for the cross, penetration and integration of the two industries (Qin, 2018).

The integration of tourism industry and cultural industry is a development process in which new products, new formats and new trends are gradually formed through the cross and mutual penetration of different factors and components between tourism industry and cultural industry or between tourism industry and cultural industry. Cultural tourism is the core of the development of tourism industry integrating culture and tourism, which is reflected in the fact that tourists not only visit the scenery, but also further understand and experience culture (Vergori \& Arima, 2020). Under the idea of integration of culture and tourism, the key to the construction of tourism industry is to integrate cultural and tourism resources and optimize them one by one, so that they can be organically combined to produce greater value, that is to achieve "win-win". Feng et al. (2013) took Yangxian Tea Culture Expo Park in Yixing, Jiangsu Province as an example to construct an evaluation index system for tea culture tourism resources, including three aspects of tea culture tourism resources characteristics, environmental characteristics and development conditions. Zhang et al., (2016) established a tourism development value evaluation system of intangible cultural heritage resources in Suzhou City, including resource endowment conditions, exhibition and experience, and tourism development conditions of heritage sites. Gao and Liu (2017) established an evaluation system for the conditions of industrialization development of marine cultural resources value, including four evaluation dimensions: resource conditions, market conditions, regional conditions and utility potential.

\section{METHODS}

Liquor culture tourism is a new business form formed by the integration of liquor industry and tourism industry. The research on the integration of liquor industry and tourism industry began in September of last century In the 1990s, with the first liquor tourism conference held in Australia in 1998, liquor culture tourism research has mushroomed all over the world (Getz \& Brown, 2006), including Australia (Carlsen \& 
Dowling, 2001; Carlsen \& Dowling, 2013), Canada (Williams \& Dossa, 2003), France (Thach \& CoganMarie, 2018), Chile (Sharples, 2002), etc. Resource elements mainly focus on the value of liquor culture itself, that is, resource endowment, which is the basic factor determining whether a place has the value of tourism development. Generally speaking, the more abundant the tourism resources and the higher the spatial accumulation degree, the more prominent the scale effect of tourism resources and the higher the value of the combination of tourism resources.



Figure 1. The methodology of liquor culture tourism development

For small tables, please place it within a column and bigger table be placed in a text frame spanning to both columns. Use the Table facility available within the MSWord. The font in the row header should be bold and you can use the style available from the style palette.

Market elements mainly measure the development value of liquor culture tourism from the perspective of market attraction, which is the key factor to evaluate whether the development of tourism resources can be successful, mainly including two aspects of tourist source conditions and location conditions. Tourist source conditions refer to the characteristics of tourist market that the target tourism resources may attract, including the scale, structure and economic level of tourists. Location conditions refer to the relationship between the location of tourism resources and the target market, including traffic accessibility, competition and cooperation with similar scenic spots around, and geographical location. The development of tourism resources is inseparable from the support of regional external environment, which includes hard environment and soft environment. The hard environment is the basic guarantee for the normal operation of tourism enterprises and tourists, and an important support for the success of tourism resources, including tourism facilities, medical facilities and environmental sanitation facilities. Soft environment is also an important factor to promote the development of regional tourism. This paper evaluates it from three aspects: social security, community attitude and policies and regulations.
Based on the existing research results, based on the perspective of supply and demand coordination, from the perspective of "institutional change - consumption upgrading - technological innovation", if it is inherited through practice and coexists in space, it will work together in the development process of liquor culture and tourism to ensure the continuity, mutual penetration and interaction of each stage. Nowadays, the demand for high-end liquor is also increasing year by year. At the same time, more and more people began to collect liquor, and liquor tasting has gradually become a trend (Kerma \& Ganik, 2015). On the whole, although the policy factors have certain restrictions on the liquor industry, other liquor culture has a certain erosion on the liquor market share, resulting in the liquor industry entering the cooling period in recent years. Therefore, in the current environment, how to better seize the opportunities and meet the challenges of liquor industry has become a difficult problem for enterprises, which is also the focus of this topic. Based on this, this paper tries to explore the dynamic mechanism of promoting the integration of liquor culture and tourism, and provides some reference for the development of liquor industry.



Figure 2. Dynamic mechanism of liquor culture and tourism integration development

\section{RESULTS}

The integration of liquor culture and tourism is a long-term and complex development process. This paper intends to analyze the industrial integration path from the three levels of "basic integration (resources) in-depth integration (technology and market) - value integration (function)", and seek the inflection point between each stage The effective path selection strategy should be adopted in time to guide and promote the optimization of liquor culture tourism industrial structure, and ultimately promote its high-quality development. As far as the current social culture is concerned, the social function of liquor still exists. The fundamental source of liquor demand determines the market positioning of liquor.

Therefore, based on the investigation of different consumer groups in the consumer market, this project attempts to gradually advance from three dimensions: basic integration, in-depth integration and value integration, which helps to grasp the market 
consumption trend, find the optimal path for the integration of liquor culture and tourism, and promote the high-quality development of the industry.



Figure 3. The integration development path of liquor culture and Tourism

Therefore, based on the investigation of different consumer groups in the consumer market, this project attempts to gradually advance from three dimensions: basic integration, in-depth integration and value integration, which helps to grasp the market consumption trend, find the optimal path for the integration of liquor culture and tourism, and promote the high-quality development of the industry.

\subsection{Basic Integration: Enriching and Developing Liquor Culture Tourism Products and Services}

The basis of the integration of liquor culture and tourism is that liquor culture can produce tourism attraction, but liquor culture itself is abstract and has no physical object. The reason why liquor culture is attractive is often due to the attraction characteristics generated by man-made entities. So how to realize the concrete attraction of liquor culture is the first step to be considered in the integration of the two (Carmichael, 2005). In the new era of national tourism, tourism has become the preferred leisure mode for the public, whether it is the Post-70s, 80s or 90s. Liquor is becoming more and more popular because of its social function and unique taste. When liquor and tourism are combined, the spark between them must be brilliant. However, the integration of the two is not on paper, but needs specific representation. The construction of physical objects cannot be separated from resources. Therefore, only when the resources owned by the two can create products or services that satisfy tourists through a series of processes, can the bottom foundation of the integration of liquor culture and tourism be realized. When liquor culture is constructed as a specific tourist attraction, it can meet the needs of tourists to identify or represent their identity through cultural consumption, because it is through these physical products that tourists can realize their own cultural value, interpersonal relationship and social status.
Therefore, the key to enhance the tourism attraction of liquor culture is to present the resources in liquor culture in physical form, or tourism products or tourism services. Liquor culture has a long history. Compared with the rich drinking culture, the tourism products and services integrated with liquor culture have some problems, such as single category, rough manufacture, and the regional liquor culture characteristics are not clear enough, which can not meet the growing consumption demand of tourists. Therefore, constantly enriching and developing liquor culture tourism products and services is the foundation of realizing the integration of liquor culture and tourism. Through the establishment of a special product planning department, more products or services with complete categories and outstanding cultural characteristics can be introduced.

\subsection{Depth Integration-making a Scientific and Reasonable Integration Plan}

To lay the foundation of resource integration, we need to establish the framework of technology and market integration. In this step, government guidance, scientific planning and layout, introduction and training of high-level management and technical personnel, strengthening publicity and shaping the image of liquor culture tourism can be carried out. First of all, the integration of liquor culture and tourism is a long-term and complex system engineering, and its complexity determines that the process cannot be completed jointly by liquor enterprises and tourism enterprises, which needs the support and guidance of local government departments. Government departments should give priority to the development planning of liquor culture and tourism integration, and make overall arrangements for the appropriate spatial layout; secondly, it is necessary to implement corresponding policies, laws and regulations, and under this guidance. Finally, it is necessary to give full play to the service function of government departments, promote the cooperation between liquor enterprises and tourism industry, make relevant departments establish the working concept of close communication and mutual benefit and win-win, and effectively solve the specific problems in the process of liquor and tourism integration. Secondly, nothing can leave people, high-level management and technical personnel is the key to achieve the integration of the two, so we need to actively cultivate and introduce relevant talents. In the stage of integration of liquor culture and tourism, a large number of professionals who are familiar with local liquor culture are required to provide services.

On the one hand, the integration of liquor and tourism needs professional technical personnel to implement, for example, the exploration and research of local characteristics of liquor culture resources need professional researchers, and the later operation 
management also needs professional management personnel. On the other hand, tourism products integrated with liquor culture need the guidance and introduction of service personnel to give tourists a perfect experience. Therefore, it is necessary to train professional talents and instill local liquor culture knowledge into them. Through the detailed introduction of tourists and the publicity of liquor culture tourism products and projects, the integrated development of liquor culture tourism can be better realized. Finally, by means of publicity, the tourism image of local liquor culture is shaped to realize the market integration of liquor and tourism industry. Liquor market and tourism market seem to be independent, but in fact, they have intersection, but they do not coincide. Therefore, it is necessary to integrate the two through effective publicity means. For example, for the promotion of local tourism, first of all, it is necessary to determine the long-term goal of liquor culture tourism development, develop liquor culture tourism projects with regional characteristics, promote local liquor culture to the market, shape a local tourism image with liquor culture elements as the core, and convey it to the market through propaganda, and finally realize the market integration of liquor and tourism industry.

\subsection{Value integration-the integration of two industries and the formation of new industries}

After more and more tourists are attracted by the rich and colorful liquor culture, the corresponding service demand has given birth to the relevant industry supply chain. From the perspective of industrial integration, the integration of liquor culture and tourism industry forms a new liquor culture tourism industry, which also changes the original business model. Therefore, the corresponding value proposition and functional appeal must be changed accordingly. In the past, the main functions of liquor were social communication, human exchanges, food and beverage consumption, while tourism was responsible for people's physical and mental relaxation and feeling the function of life. There are still differences in the functional demands of consumers between the two.

Therefore, the integration of liquor culture and tourism requires that liquor products and related cultural and artistic products be provided respectively in the past, and sightseeing experience products should be transformed into liquor culture as the core and displayed to tourists in the form of product objects or service experience, so as to realize the value of tourists to a greater extent, meet the new functional demands of tourists, innovate the value proposition and integrate the functional demands. After laying the foundation of resource integration and establishing the framework of technology and market integration, the integration project of liquor culture and tourism is completed by taking functional integration as roof. In fact, value integration pursues a deeper level of integration, which naturally occurs after the integration of resources, technology and market. The key lies in the need to ensure that tourism products and services are integrated with the connotation of liquor culture, can highlight the characteristics of liquor culture, and be conveyed to tourists by professionals. Finally, the value of the products or services to tourists is unified, not separated.

\section{CONCLUSIONS}

Chinese market is not only the world of liquor, in the process of liquor consumption, red liquor and beer have gradually become popular liquor. At the same time, the liquor market of international liquor industry has not been opened. Finally, the transformation of marketing methods. On the one hand, there are many restrictions on liquor advertising in China; on the other hand, due to the influence of Internet and e-commerce, the commercial performance and profits of liquor which are mainly sold by distributors and agents have declined, but this situation mainly occurs in the first and second tier cities which are more impacted by the Internet. In the face of this situation, how to adjust the marketing mode timely and effectively has become the key to the success of liquor enterprises.

Therefore, liquor culture tourism needs to break the development bottleneck and choose an efficient path of integration with tourism. First of all, it needs to make a judgment on the development of macro environment. At the same time, tourism has the advantage of natural attraction in the process of development. How to make use of the flow of people brought by tourism development, transform the tourist population into an important resource for enterprise brand publicity, product sales and expand the influence of enterprises, which is the focus of attention. Based on the dynamic mechanism, path selection and evaluation system of liquor culture and tourism integration, this paper discusses the specific path of tourism integration development, which helps to the development of liquor culture tourism.

\section{AUTHORS' CONTRIBUTIONS}

Min WEI: Conceptualization, Investigation, Writing - original draft, Writing - review \& editing, formal analysis, Supervision. Jie XU: Investigation, Writing original draft, Writing - review \& editing, formal analysis.

\section{ACKNOWLEDGMENTS}

The authors would like to thank the funding of "Research on the Integration Development of Liquor Culture and Tourism" (A2020004) for providing with all the necessary support. 


\section{REFERENCES}

[1] T. López - Guzmán, J. Rodríguez - García, S. Sánchez - Cañizares, et al., (2011). The development of wine tourism in Spain [J]. International Journal of Wine Business Research, 23(4), 374-386. DOI: 10.1108/17511061111186523.

[2] M. Zhang, (2019). Research on the Development Path of Integrated Innovation between Tourism and Cultural Creative Industry-Taking Changzhou Eco-Cultural Tourism Area as an Example [J]. American Journal of Industrial and Business Management, $9, \quad 72-81$ DOI: 10.4236/ajibm.2019.91006.

[3] Z. Qin, (2018). Research on the Integration and Development of Culture Industry and Tourism Industry of Fisherman Village in Rizhao[J]. Open Journal of Social Sciences, 06(11), 167-175. DOI: 10.4236/jss.2018.611012.

[4] W Feng, S Zhu, LI Xinghui, (2013). Evaluation of the Tea Tourism Resources Applied the AHP Method: A Case Study of Yangxian Tea Exposition in Yixing[J]. Journal of Nanjing Agricultural University, 13(01):127-134.

[5] X Zhang, YU Hu, T Chen, et al., (2016). Evaluation of tourism development value of intangible culture heritage resources: A case study of Suzhou City [J]. Progress in Geography, 35(08), 997-1007. DOI: 10.18306/dlkxjz.2016.08.009.

[6] L H Gao, Y Liu, (2017). Evaluation of marine cultural resource value and industrialization development conditions based on BP neural network: Take Shandong Peninsula Blue Economic Zone as an example [J]. Theory Journal, (05): 94$100 . \quad$ DOI: $10.14110 /$ j.cnki.cn-371059/d.2017.05.013.

[7] D Getz, G Brown, (2006). Critical success factors for wine tourism regions: a demand analysis $[\mathrm{J}]$.
Tourism Management, 27(1), 146-158. DOI: 10.1016/j.tourman.2004.08.002.

[8] J Carlsen, R Dowling, (2001). Regional Wine Tourism: A Plan of Development for Western Australia [J]. Tourism Recreation Research, 26(2), 45-52. DOI: 10.1080/02508281.2001.11081342.

[9] J Carlsen, R Dowling, (2013). Wine Tourism Marketing Issues in Australia [J]. International Journal of Wine Marketing, 10(3):23-32. DOI: 10.1108/eb008684.

[10] P W Williams, K B Dossa, (2003). Non-Resident Wine Tourist Markets: Implications for British Columbia's Emerging Wine Tourism Industry [J]. Journal of Travel \& Tourism Marketing, 14(3-4), 134. DOI: 10.1300/J073v14n03_01.

[11]L Thach, L Cogan-Marie, (2018). Wine Tourism in Burgundy, France: An Analysis of Marketing Practices [J]. Tourism Review International, 22(1):81-95.

DOI: $10.3727 / 154427218 X 15202734130468$.

[12]L Sharples, (2002). Wine Tourism in Chile. A Brave New Step for a Brave New World [J]. International Journal of Wine Marketing, 14(2):4353. DOI: $10.1108 / \mathrm{eb} 008742$

[13]B Carmichael, (2005). Understanding the liquor tourism experience for liquorry visitors in the Niagara Region, Ontario, Canada. Tourism Geographies, 7 (2), 185-204. DOI: $10.1080 / 14616680500072414$

[14] S Kerma, A .Ganik, 2015. Liquor Tourism as an Opportunity for Tourism Development: Examples of Good Practice in Slovenia. Journal of International Food \& Agribusiness Marketing, 27(4):311-323.

DOI: 10.1080/08974438.2014.940122. 